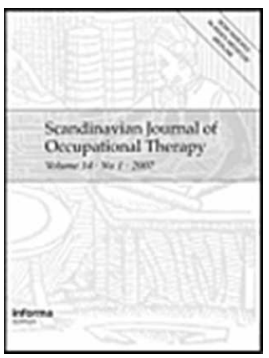

\title{
Using Photovoice as a Participatory Method to Identify and Strategize Community Participation with People with Intellectual and Developmental Disabilities
}

\begin{tabular}{|r|l|}
\hline Journal: & Scandinavian Journal of Occupational Therapy \\
\hline Manuscript ID & SOCC-2017-0169.R2 \\
\hline Manuscript Type: & Original article \\
\hline Keywords: & $\begin{array}{l}\text { community participation, barriers, supports, disability, participatory action } \\
\text { research, Photovoice }\end{array}$ \\
\hline \multicolumn{2}{|l}{} \\
\hline
\end{tabular}

\section{SCHOLARONE ${ }^{m}$}

Manuscripts 
Using Photovoice as a Participatory Method to Identify and Strategize Community Participation with People with Intellectual and Developmental Disabilities

Background: Adults with intellectual and developmental disabilities (I/DD) experience barriers to community participation, yet their insider experiences of environmental barriers and supports to participation are largely absent from the literature.

Aim/Objective: The aims of this research were to evaluate Photovoice as a participatory research method, examine environmental barriers and supports to community participation, and develop strategies to support self-determination and community participation for and with people with I/DD.

Material and Method: This study utilised a participatory action research (PAR) approach in which participants used Photovoice during interviews and audits of participation environments to identify high interest participation activities and document supports and barriers in these environments. Data analysis utilised an iterative, participatory approach in which researchers and participants teamed up to select, contextualise, and codify the data. Thematic analyses involved both inductive and realist approaches.

Results/Findings: Participants included 146 community-dwelling adults with I/DD from three U.S. urban sites. We present a conceptual model of nine themes at microsystem, mesosystem, exosystem, macrosystem, and chronosystem environmental levels.

Conclusions: Using Photovoice as a participatory method to strategize community participation can help ground systems change efforts in the voices of people with I/DD. Significance: By including people with I/DD in conversations that concern them, researchers and practitioners can support this population in ways that they find meaningful.

Keywords: community participation; barriers; supports; disability; participatory action research; Photovoice 


\section{Introduction}

Equitable access to the community, including the right to live and participate in the community with supports, are central tenets of the Disability Rights Movement, Americans with Disabilities Act (1), and Olmstead Decision (2). Even with decades of advancements in research, policy, and practice, people with intellectual and developmental disabilities (I/DD) ${ }^{1}$ continue to experience barriers to full participation in the community, having little choice and control in their employment, school, leisure, and social activities $(3,4)$. While research has identified environmental factors as barriers to participation for individuals with disabilities $(3,5,6)$, little is known about how people with I/DD experience and describe these barriers, as well as what environmental supports and strategies would improve their participation (6).

How community participation is operationalised and measured impacts both research and practice, which in turn impacts the daily lives and participation of people with I/DD. Community participation is frequently measured via quantitative assessments of performance or qualitative methods relying on professional observations. Although these methods obtain useful data about community participation outcomes, they do not take into account people with I/DD's self-defined values and

\footnotetext{
${ }^{1}$ People with intellectual and developmental disabilities is the preferred word choice of People First and SABE, two disability advocacy communities run by and for people with I/DD, so this term was used in this PAR research project with these communities. Additionally, in the United States, intellectual disability is defined as: 'a disability characterized by significant limitations both in intellectual functioning (reasoning, learning, problem solving) and in adaptive behavior, which covers a range of everyday social and practical skills. This disability originates before the age of 18 (or up to age 22 as determined by evaluator)' (2729).
} 
barriers that interfere with their performance. Little is known about how people with I/DD experience barriers and supports in their communities and how they work around barriers when they are encountered. There is a need for researchers to actively involve people with I/DD in order to understand their experiences, perspectives, and preferences.

Participatory action research (PAR) offers strategies for developing long-term, authentic partnerships with research participants with disabilities, providing a model for their inclusion in all aspects of society and acknowledging their power to direct policy and practice initiatives $(5,7,8)$. PAR emphasises the active involvement of participants throughout the research process, from shaping the research questions, to providing member checking, to serving as key informants and co-authors. PAR can be used to inform the authenticity and social validity of participation evaluation methods, ensuring that the outcomes are meaningful and useful to people with I/DD. The purpose of this study was to use a PAR approach to understand environmental barriers and supports to participation, as experienced and identified by people with I/DD.

\section{Photovoice}

A common barrier to including people with I/DD in research is a lack of accessible participatory research activities. Photovoice is an accessible PAR data collection method that involves giving participants cameras to take pictures of a specific topic to represent their experience in that domain $(9,10)$. Photovoice is used to actively engage participants who may have difficulty articulating their thoughts verbally (11). In this way, it is also a means of engaging and empowering people who historically have been left out of research. The photos are used to facilitate critical dialogue through group discussion as participants reflect on their experiences. The approach is intended to support participants to explore challenges and possibilities in a way that can improve 
their future participation. Photovoice findings are intended to reach policymakers to facilitate systems change (12). Therefore, Photovoice should result in action at the individual, community, and broader policy levels to improve integration and participation of people who have experienced marginalization.

Photovoice has been shown to be a useful tool for conducting research with people with I/DD who may have difficulty with standard data collection methods (e.g. surveys, interviews, focus groups) that may not be accessible to people with I/DD (1214). By enabling participants with I/DD to tell their story through photographs, Photovoice may also help to reduce acquiescence, a phenomenon in which individuals with I/DD who want to please the researcher simply agree with what the researcher asks (9).

\section{Methods}

This study utilised a PAR approach to explore participation as defined and experienced by and with people with I/DD from their insider perspective. The data presented in this paper were collected as part of a larger research project that examined barriers and supports to meaningful community participation for people with I/DD $(6,15-17)$. People with I/DD were involved in all study activities, from needs assessment to outcome evaluation to knowledge translation (15). This paper presents findings from the larger research project related to the following three aims: 1) To evaluate an accessible, participatory action research method of using Photovoice to illustrate community participation as experienced by people with I/DD; 2) To examine environmental barriers and supports to community participation; and 3) To action plan strategies for improving participation choice, control, and goal attainment and supports to community participation.

\section{Participants}


Participants were recruited via purposeful criterion sampling (18) through three collaborating community sites in [THREE CITIES REMOVED FOR REVIEW]. Community agencies referred eligible participants to the researchers. Participants were 146 community dwelling adults age 30 or older who were diagnosed with I/DD and were receiving community living supports and services to remain in the community and out of nursing homes and institutions. They were diverse in age, gender, and race/ethnicity (see Table 1). Several used assistive technologies, such as mobility aides or wheelchairs for community mobility and augmentative communication technology to communicate during the project. The majority of participants had an income of less than $\$ 12,000$ a year and were receiving public income assistance .

[Table 1 here]

The study was reviewed and approved by the Institutional Review Board of [UNIVERSITY NAME]. All participants provided written informed consent either by themselves or though legal guardians. Data were stored on a secure, password-protected server at [DEPARTMENT].

\section{Data collection}

The study was carried out in two participatory action research phases. In Phase 1, 146 participants with I/DD and their self-designated and invited close supports (family, staff, personal attendants) participated in interviews with the research team. During interviews, participants and their supports identified activities in specific participation sites (home, community, work/learning) that participants had difficulty doing, had stopped doing, or never had an opportunity to try. A participatory, accessible approach for choosing high interest activities was developed, using photos, magazines, and home and neighbourhood walk-throughs to support participants in choosing activities. Participants then chose and set goals related to participating in their activities of 
interest. Researchers took notes during interviews, capturing participants' direct quotations, and documented their observations via field notes after each interview.

In Phase 2, 146 participants conducted audits of participation environments with the support of access specialists (trained occupational therapy and disability studies students and Americans with Disabilities Act centre staff) and peer mentors with I/DD. Photovoice was used to actively engage participants in this process. First, participants were trained in how to use digital cameras and were asked to take pictures during various environmental audits to document what worked (supports) and what did not work (barriers). Additionally, access specialists coached participants on how to evaluate accessibility (physical, auditory, visual, cognitive, communication, and social) in diverse community settings. People with I/DD who were already active community members served as peer mentors during this session. The peer mentors instructed participants' invited supports on strategies for transferring control and choice to people with I/DD. The invited supports were taught how to support self-determination for individuals as well as the social group of people with I/DD who were going out as a team to participate. Second, all participants completed a home audit, which included a full house and room by room evaluation of accessibility and safety, as well as an assessment of engagement in activities of choice in the home (e.g. meaningful participation in activities and roles of choice, level of independence and control in decision making). This home visit was led by the participants with I/DD, who directed researchers to take photos of them, their home, and their activity likes/dislikes and choices. Third, participants, access specialists, and peer mentors conducted community participation audits related to the participants' previously chosen community participation goals of interest. Participants with similar participation goals could choose to go on outings together in small groups, typically ranging in size from 3-6 people. 
Access specialists and peer mentors met participants at their homes and travelled to community sites together, evaluating how participants got to the site (e.g. walking or taking public transportation, paratransit ${ }^{2}$, or private transportation), and their participation at the site (e.g. shopping at a store, eating at a restaurant, visiting a museum, socially interacting with people in the public). Community participation goals focused on diverse settings and activities (see Table 2).

[Table 2 here]

\section{Photovoice}

In this study, Photovoice served both as a research method and as a participatory action strategizing tool for the study participants and their social supports $(10,19)$. We chose Photovoice as a participatory action tool in order to support participants and their social supports to provide feedback to their communities, businesses, and the public about the need for increased cognitive accessibility in order to better support the participants' participation.

We utilised a number of adaptations in order to make Photovoice more accessible for our study participants. For example, we provided accessible digital cameras, as opposed to disposable cameras, because they provided large screens so participants could see their photos instantaneously for feedback and validation. Digital cameras were simple to use and enabled participants to take as many photos as they wanted without errors or expensive production, and they facilitated easy printing at community agencies to see and sort. Additionally, participants could choose to take photos themselves or to direct other people (e.g., peers, peer mentors, or social

\footnotetext{
${ }^{2}$ Americans with Disabilities Act (ADA) complementary paratransit service is a door-to-door transportation service for people who are unable to use accessible fixed route transportation services due to disability.
} 
supports) to take photos of them participating in an activity. This enabled participants to document environmental barriers and supports, as well as participation strategies and accommodations. Finally, by providing participants with a photobook of the photos they selected, they were empowered in their ability to share them with other people, such as their social supports, friends, caregivers, family members, or service providers, to convey what supported or hindered their participation as well as what they would like to see in their communities to improve cognitive accessibility.

\section{Data analysis}

We used an iterative approach to participatory analysis, adapting the approach outlined by Wang and Burris (10) (i.e., selecting, contextualising, codifying) in order to make it accessible for the participants. First, after each community participation visit, the participants met in the same small groups. With support from the research team, participants were encouraged to select the photos that best showed barriers and supports.

Next, the research team encouraged the participants to contextualize the photos they had chosen by arranging them to tell the story they wanted to tell. This stage of analysis often includes group discussion, reflecting both individual and collective experience. The research team supported the participants to arrange their photos to tell a story by using a simplified version of the SHOWeD approach, which asks participants to discuss the following questions: What do you See here? What's really Happening here? How does this relate to Our lives? Why does this problem or this strength exist? What can we Do about this? (20). We modified the questions as follows: What do you see here? What's really happening here? What support or problem does this show? Research team members adapted typical Photovoice analysis, wherein participants themselves write down captions for their photos, by recording participants' quotes and 
phrases, making it more accessible for the study participants. When participants were unable to verbalize descriptions of the photos, their participation in selecting and arranging photos constituted an adaptation to the analytic process. We created photobooks for each participant with the photos they had chosen, including captions when applicable, and each participant kept their photobook.

For the final step of analysis, codifying, the research team analyzed the photos with captions and researchers' notes using Braun and Clarke's (21) approach to thematic qualitative analysis. We used two specific thematic analysis approaches: 1) Inductive, or data driven, wherein researchers code data without attempting to fit it into an existing coding frame rather than being driven by a particular theoretical framework, resulting in themes that are strongly linked to the data themselves; and 2) Realist, or essentialist, which reports the experiences, meanings, and reality of the participants themselves. Using these approaches, two researchers independently analysed the data and met to discuss their analyses, establishing a preliminary framework to understand the potential relationships between codes and discussing and resolving differences. This was followed by an iterative process of discussion, revision, and grouping the codes into themes.

\section{Results}

The themes that emerged were interconnected, clustered under broader themes of the physical, social, and economic environments, and community participation. Sub-themes included home environment, community environment, peer social support and mentoring, societal attitudes, staff and family policies and practices, money and finances, community opportunities, community access to technology, and personal transportation options (see Table 3). The following section presents the themes as they emerged from the interview and Photovoice data. 
[Table 3 here]

\section{Physical environment}

Home environment

Participants identified the physical environment as a potential support or barrier to community participation. Participants typically chose to begin their Photovoice books with photos of their homes, such as their bedrooms decorated with their hobbies and interests, signifying their choice and control in their room décor and free time.

Participants spoke about how they valued being out in the community. They had framed photos of past community outings on display in their homes, and some took photos of these displayed photos to signify a support to community participation. Some participants took photos of dresser drawers that had been labelled by clothing item for ease of use, and signs with pictures that helped participants to express their needs. Additionally, participants took photos of inaccessible parts of their homes, such as steep steps leading to their front door or within the home, poor lighting outside or inside the home, and the absence of hand railings or grab bars in bathrooms.

\section{Community environment}

Participants indicated that the community environment afforded both supports and barriers to participation. Participants' photos documented accessible aspects of the community, such as public zoo interactive maps with pictures, audio, and clear directions with large arrows. One participant who uses a wheelchair took a photo of a zoo sign with an accessible button, captioning the photo, 'I pushed it myself.' However, the natural environment and weather were common barriers to participation, indicated by photos of large rain puddles or snow blocking sidewalks, forcing them-participants to walk in the road. Cold weather was also a barrier; a photo depicting peers huddling together to stay warm was captioned, 'So windy waiting [for the train].' Other barriers 
depicted in photos included large cracks in the sidewalk, inaccessible signage and maps, motor vehicles parked in the middle of the sidewalk path, bus stop signs lying on the ground, busy intersections without traffic lights, and steep, poorly lit subway stairways. Captions to such photos read, 'Had to walk upstairs because of broken elevator,' 'Crossing without lights - dangerous! Busy crosswalk without lights' (Figure 1a) and 'No crosswalk, walking through traffic to get to bus stopWe can't read this map.' (Figure 1b).

[Figure 1 here]

\section{Social environment}

Peer social support and mentoring

Many of the participants' photos documented peer support as a facilitator to participating in the community. Some depicted the value of merely being together, such as peers laughing together while riding the bus and spending time together at the zoo. Photo caption examples include 'Eating lunch together' and 'We go on the bus together.' In an interview, a male participant said he wanted to 'be with my friends.' Photos also documented specific ways peers helped each other, such as linking arms while walking through crowded areas; waiting for everyone to finish paying for their meal at a restaurant before sitting down to eat; and helping each other fill out library card applications, use a vending machine, use a bus pass, and choose the right clothing size while shopping. Photo captions include 'helping fill out library card' (Figure 2a), 'I like to show [my peer] how to take pictures' (Figure 2b), 'It was nice showing [my peer] how to get on the bus,' and 'Your money ran out - I'll give you some of mine and help you use the machine.'

[Figure 2 here]

Societal attitudes 
Participants depicted and described community members as a potential support or barrier to community participation. For example, photos depicted helpful bus drivers assisting participants with bus fare or lowering the bus for participants to step on more easily. Some establishments were welcoming of people with I/DD, like a professional baseball stadium that agreed to schedule a private tour for participants at no cost during a time when it would not be crowded. Participants took photos of their tour guide, who they said provided information about the stadium in an accessible manner. Other photos included eashiers-customer service representatives who were helpful as participants purchased-shopped lunch-for electronics (Figure 3) or waitresses who were patient as participants ordered their food. Conversely, participants also took photos of unhelpful bus drivers and cashiers. Participants' family members reported concerns about how participants were treated while out in the community; a father who said that his son did not go out because 'it's not safe' and 'you can't trust people like you used to.' One participant identified attitudinal barriers, saying that she would likely not be hired at a fast food restaurant despite her history of work-related awards. Although a few participants discussed societal-level attitudinal barriers, researchers noted that few had opportunities to interact with the public at all.

[Figure 3 here]

\section{Staff and family policies and practices}

Participants' photos depicted ways in which group home staff supported their community participation, such as helping participants across busy intersections, pushing the wheelchair of a participant whose health issues caused them to become easily fatigued, and assisting participants with public transportation. Examples of photo captions include, 'Had a good conversation [with staff]' and '[Staff] supporting [me] to walk down the steps.' However, participants expressed frustration with the lack of 
choice and control they were afforded by group home policies, and by individual staff or family members. In an interview, a male participant said, 'I wish I could go bowling. I have my own bowling ball. Staff won't let me.' He stated that 'staff members plan all of the outings' for the entire group rather than giving participants control to plan activities according to their individual preferences. Similarly, other participants said that they were unable to engage in activities because they did not have enough money, stating that they were required to spend their weekly allowance on purchasing snacks at the group home. They were unaware that they had the right to save and spend their money however they wished. Some participants reported that an agency policy prevented them from purchasing bus passes because taking public transportation was considered a threat to participants' safety. The research team worked with direct support staff to educate them on participants' rights, including the right to use their money as they desired.

Rules about curfew and the need to obtain permission for activities presented barriers to participants' right to the dignity of risk, to partake in their 'fair share of risk experiences' (22). One participant liked to 'ride my bike around and go out to eat' but had to 'be back in before dark,' restricting his participation based on others' estimation of risk. Another participant's mother was not comfortable with him going places without supervision. Similarly, a researcher noted that a different participant's parents 'do not allow for a degree of risk. He would like to get a job and visit his girlfriend, things his parents do not encourage.'

\section{Economic environment}

Money and finances

Participants' photos and interviews indicated that money and personal finances were frequently a barrier to community participation. Although participants were eager to 
engage in community activities, they often lacked the financial ability to do so. Many were conscious of the need to manage their money, with photo captions such as, 'We brought our lunch to save money.' Despite these efforts, however, they were still unable to participate in certain community activities because they lacked enough money. For example, a group of participants wanted to go on a boat tour of the city, but ticket prices were too expensive. A participant's photo of the boat fair ticket price was captioned, 'WOW! That's way too much!' A male participant noted in an interview, 'I just wish I had more money, that's all.' He had enough money to take transportation out into the community but not enough to participate once there. Financial barriers forced some participants to make difficult decisions. A female participant's sheltered workshop redistributed her work if she was not present during the workday to complete it. This presented a quandary for her: She wanted to go out in the community during the daytime (when there were more opportunities and when she was allowed to be in the community), but if she did, she would risk losing work and money. At the same time, she considered a sheltered workshop to be her only work opportunity, but because it paid less than minimum wage, she did not have much money to participate even when she did work.

A male participant recognised work as both a participation opportunity itself and a means to access other participation opportunities. He wanted to 'work, make money, not worry' and to find a 'real job' which, unlike his current sheltered workshop job, would be fulfilling and give him more money to increase his participation opportunities. A researcher observed in a field note, 'The system places people with I/DD in sheltered workshops rather than in integrated work environments.' Another researcher's field note indicated that 'Sheltered workshop jobs do not allow [participants] to earn enough money to even cover the cost of transportation to get there.' 
Environmental barriers were sometimes caused by a lack of support for disability-related needs. For example, one participant initially worked three-hour shifts at her job, where someone assisted her with toilet transfers. When her employer stopped offering this assistance, she had to reduce her shift length and wear absorbent undergarments, neither of which were her choice.

\section{Community participation}

\section{Community opportunities}

Participants depicted their opportunities for engaging in community activities, such as doing crafts, watching plays, going to the zoo, and going to the city for seasonal activities like looking at holiday decorations and participating in Halloween events. Examples of photo captions include 'Playing in the fountain,' 'Looking at [zoo] animals,' 'Trying to decorate a pumpkin,' and 'At the movies. I liked the movie we saw, the Guardians. I ate popcorn.' Participants took advantage of local activities that were low cost or free, and staff supported them by organizing the outings. They found value in participating in enriching and fun activities, in stark contrast to routine activities like self-care and chores. Meaningful participation was supported when participants were able to be part of a community in a mutually beneficial way. As a male participant noted, 'I like to go to the fire department. I know the fire department and I help them.' The fire department was not only a place for social engagement but also service. Others wanted to be peer mentors to other people with I/DD; a female participant found it meaningful to 'get a job...work in hospitals with patients, take them for tests.' Although another participant liked working in a sheltered workshop, she wanted to return to a community-based janitorial position that was more meaningful to her.

However, participants often had limited access and opportunities to do the things they most needed and wanted to do. It had often been years since they had done valued 
activities, or they only did them on a 'one shot' basis with a group of people with I/DD rather than directing their own participation. Participants said that they wanted to have the freedom to choose how and when they participated in activities that were meaningful to them, and they wanted a say in how much independence they had. A female participant wanted to live in a house with a roommate where 'someone would stop in once in a while and check on me--but not 24-hour supervision. Somewhere where I could have friends come over.' Participants were not demanding total control but instead wanted more control over activities that they perceived as most important.

\section{Community access to technology}

Participants viewed technology as a support when they were able to access it within the community. Participants took photos of touch screens they used when purchasing bus passes through a kiosk. Some found digital cameras to be a support, as they were able to look at the photos they had just taken to determine if they liked the photo or wanted to take another one. However, technology was inaccessible in two ways: 1) Technology

manuals, instructions, or display counters were inaccessible (Figure 4a), and 2) Devices themselves were inaccessible (i.e. phone keypad was too small). Participants' photos indicated that they wanted to purchase cell phones but found information about the phones and phone plans to be inaccessible. For example, a participant captioned their photo 'trying out the cell phones- none work' (Figure 4므).

[Figure 4 here]

\section{Personal transportation options}

Participants' photographs documented ways that transportation supported their participation, including photographs of buses, paratransit, taxis, and agency vans, with captions such as, 'Used the [wheelchair] lift to get out of van.' One participant and her housemates used the paratransit bus on a daily basis because 'without them we would 
be stuck.' A lack of access to transportation was often a barrier to participation, indicated by photos of bus signs where needed routes were not in service (Figure 5a) and large steps that made it difficult to board a bus (Figure 5b). One participant captioned a photo, 'Waiting for our taxi to come back and get us,' as there was no bus service from the movie theatre back to the group home. Some participants missed planned outings because taxi drivers rejected their discounted fare vouchers. A few participants reported delays in receiving their monthly public transportation passes, while others did not know how to get a monthly pass or to set aside resources to purchase one. Still others lamented the unreliability of paratransit services, which caused them to be late to or miss appointments and events altogether.

[Figure 5 here]

\section{Discussion}

The purpose of this study was to evaluate Photovoice as a participatory method of illustrating community participation as experienced by and with adults with I/DD, to understand environmental barriers and supports to community participation, and to action plan strategies for improving participation choice, control, and goal attainment and supports to community participation. Participants with a range of disabilities in a previous study who were living independently in the community defined participation as involving respect and dignity (5). Unlike these individuals, the participants with I/DD in our study were living in group homes or with family members, primarily participating in routine activities that were orchestrated for them and rarely interacting with the public. It is therefore unsurprising that participants in this study defined participation primarily as getting out into the community; it may be that the link between participation and respect and dignity emerges only after basic participation needs are met. 
The participatory and accessible research activities in our study enabled participants to identify barriers and supports to participating in their community, from their own perspectives and experiences. Through Photovoice, we were able to not only collaboratively identify barriers and supports, but also to understand how these are interconnected, as described below.

\section{Findings through the lens of Bronfenbrenner's bioecological model}

Bronfenbrenner's (23) bioecological model provides a basis for describing the interplay between different levels of the environment and their effects on community participation. According to this model, a person is simultaneously affected by five nested and interacting environmental systems: the microsystem, mesosystem, exosystem, macrosystem, and chronosystem. Participants in this study identified a variety of factors that impact their participation, ranging from microsystem-level to macrosystem-level factors (see Figure 6).

[Figure 6 here]

Participants' community participation was impacted by their experiences in several microsystems - their patterns of roles, activities, and interpersonal interactions experienced in a given setting (23). Microsystem settings that participants frequently discussed include their home, workplace, and community environments. As described earlier, participants discussed both barriers and supports within these individual microsystem-level settings that impacted the extent to which they participated to their satisfaction. Supports and barriers included both objects and people they interacted with. For example, when researchers asked participants about the decorations in their rooms such as photos or souvenirs, participants excitedly described previous outings they had enjoyed, discussing future possibilities for community participation. In this way, objects in participants' homes served as a support to community participation at 
the microsystem level. Other microsystem level facilitators included accessible signage and peer support, such as when participants helped each other to use cameras on community outings. Conversely, some participants described microsystem-level barriers such as cashiers being unhelpful or impatient, restricting their ability to fully participate in that setting.

Participants' mesosystems - interactions between two or more microsystems in which the person participates actively (23) —included peer social support and mentoring, money and finances, family and staff policies and practices, and personal transportation options. This was seen in participants supporting and mentoring each other across microsystem settings, such as while navigating public transportation or using cameras to take photos on community outings. Although participants used money they earned in their sheltered workshop settings to participate in community outings, the amount of money they earned was often not enough for them to participate in the way they wanted, thus presenting a mesosystem-level barrier. For some participants, interactions between microsystems prevented them from participating in certain activities of choice; for example, restrictive group home policies and staff practices prohibited participants from going bowling or going out after dark.

The exosystem - in which people do not participate actively but which affects a person's microsystems (23) — impacted participants by way of community opportunities, community natural environment and weather management, and staff, family, and government rules and policies. For example, participants did not engage in group home policy development, but as evidenced earlier, these policies affected group home staff practices within participants' microsystems (e.g., not being able to participate in the community after dark). Additionally, participants were not directly involved in weather management efforts, but sidewalks that were not shovelled impeded 
their ability to navigate their community environment. Participants experienced an exosystem-level support in the form of low-cost and free activities, which were likely developed by state and local businesses, organizations, and community members and provided numerous opportunities for participants to engage in the community.

The macrosystem — which encompasses patterns of similarity and difference both within and across the lower-level systems described earlier, as well as ideologies imbedded within these patterns (23) — impacted participants by means of social conditions and societal attitudes regarding disability, labour, safety, and autonomy. This is exemplified in participants' sheltered workshop wages that hindered full community participation. Sub-minimum wages are the norm at most sheltered workshops in the United States, and participants' financial barriers are best understood in the larger construct of the political economy of disability (24). In a system that commodifies workers, purchasing their labour in exchange for wages, the work of people with I/DD is considered less valuable surplus labour and is thus exchanged for sub-minimum wages.

Finally, the chronosystem — how a person's previous life experiences and time in which they are living impact their development (23) - is seen in the community-based settings in which participants lived. These settings, the result of de-institutionalization, strongly influenced their participation. Additionally, several participants noted that they wanted to become peer mentors in the future as a result of their current experience with peer mentorship during this study, exemplifying how current experiences may influence future experiences.

\section{Practice and policy implications}

The values and barriers identified by participants in this study provide insight into how researchers and practitoners can support people with I/DD to participate in their 
communities in ways that are meaningful to them. Our findings indicate that supports and barriers to community participation for people with I/DD exist not just at the level of the immediate (microsystem level) environment, but also across settings (macrosystem level), in environments that people do not engage in but which nonetheless impact them (exosystem level), as well as at the societal (macrosystem) level. Further, previous life experiences, historical events and movements, and the time in which the person is living impacts their engagement (chronosystem level).

Practitioners can support community participation for people with I/DD by working to mitigate barriers at all environmental levels. For example, practitioners can offer money management, assertiveness education, and assistive technology skill acquisition. Practitioners can also support enfranchisement and collective empowerment by facilitating peer mentor/mentee relationships for people with I/DD, which can support them to achieve their participation goals.

Additionally, our findings reveal how participants' experiences at the microsystem level should be understood as manifestations of more pervasive, broader societal issues. While mitigating immediate barriers can improve individual participation, reflecting on their root causes can facilitate change on a broader level. For example, our findings raise questions about the common placement of people with I/DD in sheltered workshops, the extent to which such assignments limit people with I/DD's financial freedom and community participation, and the lack of opportunities they have for experiencing dignity of risk. Rather than focusing attention and resources solely to improving institutional living and sheltered workshop conditions, however, advocacy work can target increasing affordable, accessible, community-based housing options and integrated employment opportunities for people with I/DD, supporting them to live, work, and participate in their communities as desired. 
Finally, the lack of access to one's own money is problematic at mesa and micro levels. Most participants in the study were given small 'allowances' of their own money each week and told what to spend it on, leaving them without money to use in the community. Restrictive institutional policies, as well as group home staff members' interpretation of policies or manner of exerting authority over people with I/DD, prevent these individuals from participating in their communities the way they choose, which is a violation of their civil rights (6). This applies also to family members who have full decision making power over which activities they perceive as 'safe' and 'acceptable' for their family member with I/DD. Practitioners can educate individuals with I/DD about their right to save and spend their money as they choose. Institutional policies should be written so as to allow individuals with I/DD the dignity of risk related to participation.

Disability advocacy groups can be a resource for people with I/DD for learning to advocate for system-level changes that support their participation (6).

\section{$\underline{\text { Limitations and Future Directions }}$}

Collecting data that accurately reflects the views of people with I/DD is a challenge of conducting research with this population. In order to address this challenge, the current study used several participatory tools to avoid participant acquiescence and ensure that participants were able to actively engage alongside researchers throughout the data collection process. For example, the study used $\underline{\text { Photovoice, goal setting, and audits of home and community participation environments }}$ $\underline{\text { to give participants opportunities to engage in in-context conversations about }}$ participation instead of needing rely on memory to recall how they experienced participation in the past. Direct quotations were gathered to ensure that participants' voices were accurately captured in the photobooks that they were creating. 


\begin{abstract}
Although participants were actively involved in the first two steps of data analysis, the researchers acknowledge that participants were not involved in the third and final step (codifying), and that the study did not utilise an inclusive authorship approach. Other participatory researchers have noted similar limitations related to $\underline{\text { sharing control and power over the research process due to technical and oftentimes }}$ $\underline{\text { tedious analytic processes and differing values and motivations for dissemination of }}$ findings $(13,16)$. To address this limitation, during the first two steps of data analysis participants selected photos that best represented barriers and supports they experienced while participating and arranged them to tell their desired story of what was happening in the photos and what supports or problems the photos were showing. Then, in the third $\underline{\text { step, researchers used inductive and realist approaches to codifying the data in order to }}$ ensure that themes were tied directly to the data and were reflective of participants' $\underline{\text { lived experiences and realities. }}$
\end{abstract}

Finally, the study's findings may not generalize to other adults with I/DD and may only reflect the experiences and perspectives of this particular group of participants. Participants in the current study had mild to moderate I/DD and were $\underline{\text { living in urban areas. Furthermore, the study did not differentiate between men and }}$ women and whether these two groups define and experience participation differently. Thus, future research should continue to examine how people with I/DD experience and define participation and should explore the experiences of people with severe I/DD as well as those living in rural areas. However, it is important to note that the goal of PAR is not generalizability; instead, PAR is concerned with confronting traditional power $\underline{\text { relations and facilitating change as prioritized by marginalized community members }}$ $(25)$

\title{
Conclusion
}




\begin{abstract}
Although recent gains in research and practice support community participation for people with I/DD, there is a need for further progress in this area (26). These findings reveal how community-dwelling participants with I/DD defined and experienced supports and barriers to participation. Our participatory methods aimed to highlight the voices of people with I/DD, who have historically been left out of conversations that concern them. By using participatory methods such as Photovoice to ground systems change efforts in the voices and experiences of people with I/DD, researchers and practitioners can work to reduce barriers, improve opportunities, and support full community participation for this population in ways that they find meaningful.
\end{abstract}




\section{References}

1. U.S. Department of Justice. The Americans with Disabilities Act [Internet]. 101336, 104 Stat. 328 1990. Available from: http://www.ada.gov/2010_regs.htm

2. Olmstead v. L. C. 527 U.S. 581, 119 S.Ct. 2176 [Internet]. 1999. Available from: https://www.ada.gov/olmstead/olmstead_about.htm

3. Verdonschot MML, de Witte LP, Reichrath E, Buntinx WHE, Curfs LMG. Community participation of people with an intellectual disability: A review of empirical findings. J Intellect Disabil Res. 2009;53(4):303-18.

4. Amado AN, Stancliffe RJ, Mccarron M, Mccallion P. Social inclusion and community participation of individuals with intellectual/developmental disabilities. Intellect Dev Disabil. 2013;51(5):360-75.

5. Hammel J, Magasi S, Heinemann A, Whiteneck G, Bogner J, Rodriguez E. What does participation mean? An insider perspective from people with disabilities. Disabil Rehabil. 2008;30(19):1445-60.

6. Hammel J, Jones R, Smith J, Sanford J, Bodine C, Johnson M. Environmental barriers and supports to the health, function, and participation of people with developmental and intellectual disabilities: Report from the State of the Science in Aging with Developmental Disabilities Conference. Disabil Health J. $2008 ; 1: 143-9$.

7. Caldwell J, Heller T. Longitudinal outcomes of a consumer-directed program supporting adults with developmental disabilities and their families. Intellect Dev Disabil. 2007;45(3):161-73.

8. Stevenson M. Participatory data analysis alongside co-researchers who have Down Syndrome. J Appl Res Intellect Disabil. 2014;27:23-33.

9. Booth T, Booth W. In the frame: Photovoice and mothers with learning 
difficulties. Disabil Soc. 2003;18(4):431-42.

10. Wang CC, Burris MA. Photovoice: Concept, methodology, and use for participatory needs assessment. Heal Educ Behav. 1997;24(3):369-87.

11. Wang CC, Cash JL, Powers LS. Who knows the streets as well as the homeless? Promoting personal and community action through Photovoice. Health Promot Pract. 2000;1(1):81-9.

12. Jurkowski JM, Paul-Ward A. Photovoice with vulnerable populations: Addressing disparities in health promotion among people with intellectual disabilities. Health Promot Pract. 2007;8(4):358-65.

13. Povee K, Bishop BJ, Roberts LD. The use of photovoice with people with intellectual disabilities: Reflections, challenges and opportunities. Disabil Soc. 2014;29(6):893-907.

14. Jurkowski JM, Rivera Y, Hammel J. Health perceptions of Latinos with intellectual disabilities: The results of a qualitative pilot study. Health Promot Pract. 2009;10(1):144-55.

15. Garcia-Iriarte E, Kramer JC, Kramer JM, Hammel J. "Who did what?”: A participatory action research project to increase group capacity for advocacy. $\mathrm{J}$ Appl Res Intellect Disabil. 2009;22:10-22.

16. Kramer JM, Kramer JC, García-Iriarte E, Hammel J. Following through to the end: The use of inclusive strategies to analyze and interpret data in participatory action research with individuals with intellectual disabilities. J Appl Res Intellect Disabil. 2011;24(3):263-73.

17. Zakrajsek AG, Hammel J, Scazzero JA. Supporting people with intellectual and developmental disabilities to participate in their communities through support staff pilot intervention. J Appl Res Intellect Disabil. 2014;27(2):154-62. 
18. Patton MQ. Qualitative research and evaluation methods. 4th ed. Los Angeles: Sage Publications, Inc.; 2014.

19. Wang CC. Photovoice: A participatory action research strategy applied to women's health. Vol. 8, Journal of Women's Health. 1999. p. 185-92.

20. Wang CC, Yi WK, Tao ZW, Carovano K. Photovoice as a participatory health promotion strategy. Health Promot Int. 1998;13(1):75-86.

21. Braun V, Clarke V. Using thematic analysis in psychology. Qual Res Psychol. 2006;3(2):77-101.

22. Perske R. The dignity of risk. In: The principle of normalization in human services. Toronto: National Institute on Mental Retardation; 1972. p. 194-200.

23. Bronfenbrenner U, editor. Making human beings human: Biological perspectives on human development. Thousand Oaks: Sage Publications; 2005.

24. Charlton JI. Nothing about us without us: Disability oppression and empowerment. Berkeley: University of California Press; 1998.

25. Freire P. Pedagogy of the Oppressed. 30th anniv. New York, NY: Continuum; 1970.

26. Cummins RA, Lau ALD. Community integration or community exposure? A review and discussion in relation to people with intellectual disability. J Appl Res Intellect Disabil. 2003;16:145-57.

27. Schalock RK, Borthwick-Duffy SA, Buntinx WHE, Coulter DL, Craig EM, Gomez SC, et al. Intellectual disability: Definition, classification, and systems of supports. Vol. 11th ed. Washington, DC; 2010.

28. American Psychiatric Association. Diagnostic and statistical manual of mental disorders: DSM-5. Washington, DC: American Psychiatric Association; 2013.

29. 106th Congress. Developmental Disabilities Assistance and Bill of Rights Act of 
2000. p. Public Law 106-402. 
Table 1. Demographics of participants with I/DD characteristies ( $\mathrm{n}=146)$.

\begin{tabular}{llcc}
\hline Demographics & & Frequency & Percent \\
\hline Gender & Male & 84 & 57.5 \\
& Female & 61 & 41.8 \\
& Missing & 1 & 0.7 \\
\hline Race & African-American & 75 & 51.4 \\
& Hispanic & 34 & 23.3 \\
& Caucasian & 33 & 22.6 \\
& Asian & 2 & 1.4 \\
& MissingNot Disclosed & 2 & 1.4 \\
\hline Income Range & Less than \$12K per year & 110 & 75.3 \\
& MissingNot Disclosed & 30 & 20.5 \\
& \$12K or more & 6 & 4.1 \\
\hline Supports & $\underline{\text { Yes }}$ & $\underline{129}$ & \\
\hline
\end{tabular}

\begin{tabular}{llll} 
& $\underline{\text { Not Disclosed }}$ & $\underline{10}$ & $\underline{6.8}$ \\
& $\underline{\text { No }}$ & $\underline{7}$ & $\underline{4.8}$ \\
\hline$\underline{\text { Use mobility technology to get }}$ & $\underline{\text { Do not use, ambulate on }}$ & $\underline{104}$ & $\underline{71.2 \%}$ \\
$\underline{\text { around in community? }}$ & $\underline{\text { own }}$ & $\underline{20}$ & $\underline{13.8 \%}$ \\
& $\underline{\text { Use wheelchair }}$ & $\underline{22}$ & $\underline{15 \%}$ \\
\hline$\underline{\text { Use augmentative or alternative }}$ & $\underline{\text { Use cane or walker }}$ & Yes & $15 \%$ \\
$\underline{\text { communication technology to }}$ & & &
\end{tabular}


1

2

3

5

6

7

8

9

10

11

12

13

14

15

16

17

18

19

20

21

22

23

24

25

26

27

28

29

30

31

32

33

34

35

36

37

38

39

40

41

42

43

44

45

46

47

48

49

50

51

52

53

54

55

56

57

58

59

60 communicate-?

$124 \quad 85 \%$

Mean (SD)

\begin{tabular}{ll}
\hline Age & $45(13.26)$
\end{tabular}

Age

No

(13.26) 
Table 2. Phase 2 audit totals.Community Participation Goal Areas

\begin{tabular}{|l|c|}
\hline \multicolumn{1}{|c|}{ Audits } & Total \\
\hline $\begin{array}{l}\text { Home (individual solitary and social } \\
\text { participation activities in home) }\end{array}$ & 146 \\
\hline $\begin{array}{l}\text { Community Participation Sites(most } \\
\text { common goals included: going }\end{array}$ & \\
$\begin{array}{l}\text { downtown, shopping, eating out, people } \\
\begin{array}{l}\text { watching, going to the lake, using the } \\
\text { library, visiting community places and }\end{array}\end{array}$ & 244 \\
$\begin{array}{l}\text { spaces, accessing the web/internet to } \\
\text { socially network, attending sports event, }\end{array}$ & \\
$\begin{array}{l}\text { using parks and recreation facilities, } \\
\text { going out on dates) }\end{array}$ & \\
\hline $\begin{array}{l}\text { Public Community Mobility \& } \\
\text { Transportation and } \\
\text { Paratransit(navigating public and door } \\
\text { to door transportation options, access }\end{array}$ & 178 \\
\hline $\begin{array}{l}\text { and accessibility) } \\
\text { Total }\end{array}$ & 568 \\
\hline
\end{tabular}


Table 3. Overview of themes.

\begin{tabular}{|c|c|c|c|}
\hline \multicolumn{2}{|r|}{ Themes } & $\begin{array}{c}\text { Barrier or } \\
\text { Support }\end{array}$ & Examples \\
\hline \multirow{4}{*}{ 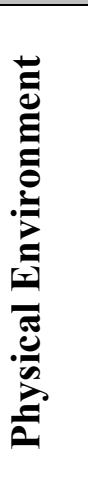 } & \multirow[t]{2}{*}{ Home Environment } & Support & $\begin{array}{l}\text { Bedrooms are decorated according to participant } \\
\text { interests }\end{array}$ \\
\hline & & Barrier & Steps in the home are too steep \\
\hline & \multirow[b]{2}{*}{ Community Environment } & Support & $\begin{array}{l}\text { Zoo signage is accessible by being interactive, } \\
\text { tactile, and having audio; Benches at train station to } \\
\text { sit on when waiting for the train }\end{array}$ \\
\hline & & Barrier & $\begin{array}{l}\text { Snow blocking sidewalks access and walkways; } \\
\text { busy intersections that do not have traffic lights; } \\
\text { mall directories and public transportation signs have } \\
\text { small font size and are hard to understand }\end{array}$ \\
\hline \multirow{5}{*}{ 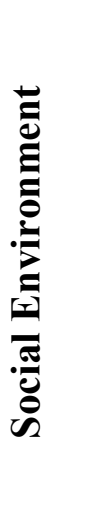 } & $\begin{array}{c}\text { Peer Social Support and } \\
\text { Mentoring }\end{array}$ & Support & $\begin{array}{l}\text { Peers link arms when walking through crowded } \\
\text { areas }\end{array}$ \\
\hline & \multirow[b]{2}{*}{ Societal Attitudes } & Support & Bus driver helps participants with bus fare \\
\hline & & Barrier & $\begin{array}{l}\text { Cashiers are unhelpful or impatient when serving } \\
\text { participants; Boss reluctant to hire participant } \\
\text { despite her history of work-related awards }\end{array}$ \\
\hline & \multirow{2}{*}{$\begin{array}{l}\text { Staff and Family Policies } \\
\text { and Practices }\end{array}$} & Support & Staff coordination during community outings \\
\hline & & Barrier & Rules limit participation \\
\hline 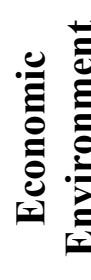 & Money and Finances & Barrier & $\begin{array}{l}\text { Participants do not have enough money to go to the } \\
\text { movies or to go on a boat tour in the city }\end{array}$ \\
\hline \multirow{6}{*}{ 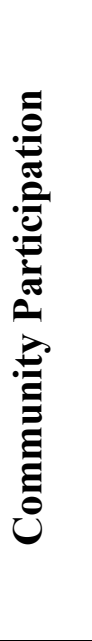 } & \multirow[b]{2}{*}{ Community Opportunities } & Support & Participants engage in community holiday activities \\
\hline & & Barrier & $\begin{array}{l}\text { Lack of choice about how and when to participate in } \\
\text { activities }\end{array}$ \\
\hline & \multirow{2}{*}{$\begin{array}{l}\text { Community Access to } \\
\text { Technology }\end{array}$} & Support & $\begin{array}{l}\text { Accessible kiosk (touch screen) to purchase bus fare } \\
\text { tickets }\end{array}$ \\
\hline & & Barrier & $\begin{array}{l}\text { Information about cell phone plans is cognitively } \\
\text { complex and print is too small to read }\end{array}$ \\
\hline & \multirow{2}{*}{$\begin{array}{l}\text { Personal Transportation } \\
\text { Options }\end{array}$} & Support & $\begin{array}{l}\text { Agency van makes it easier to participate in } \\
\text { community activities }\end{array}$ \\
\hline & & Barrier & $\begin{array}{l}\text { Limited availability and reliability of transportation } \\
\text { options; Some participants were not familiar with } \\
\text { using public transit }\end{array}$ \\
\hline
\end{tabular}




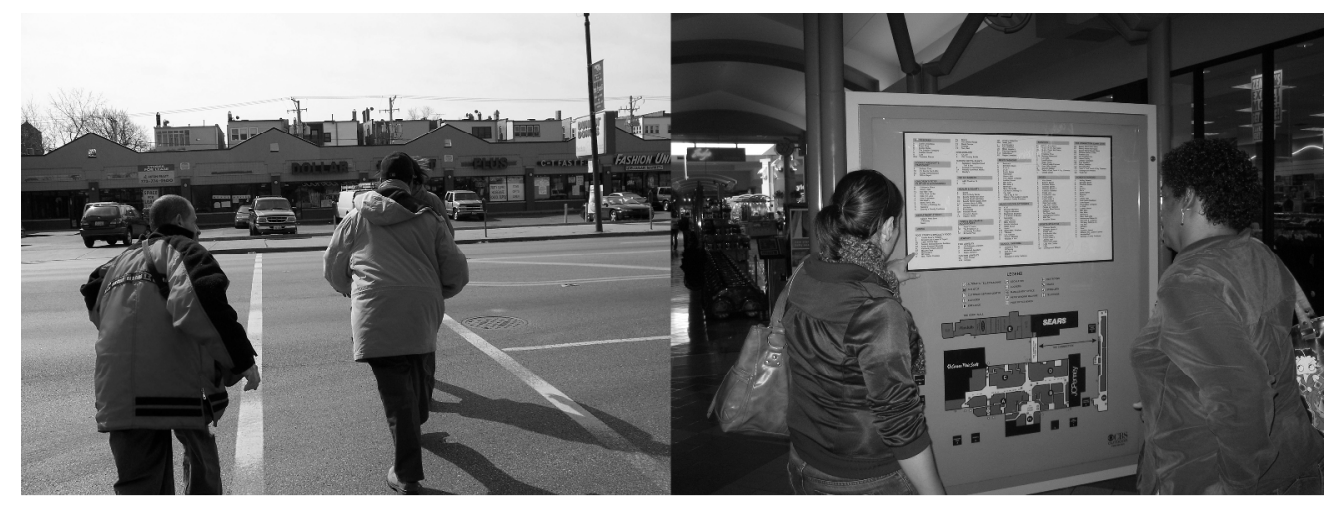

Figure 1. Barriers in the community environment as depicted by participant photographs: 'Busy crosswalk without lights' and 'We can't read this map.' 


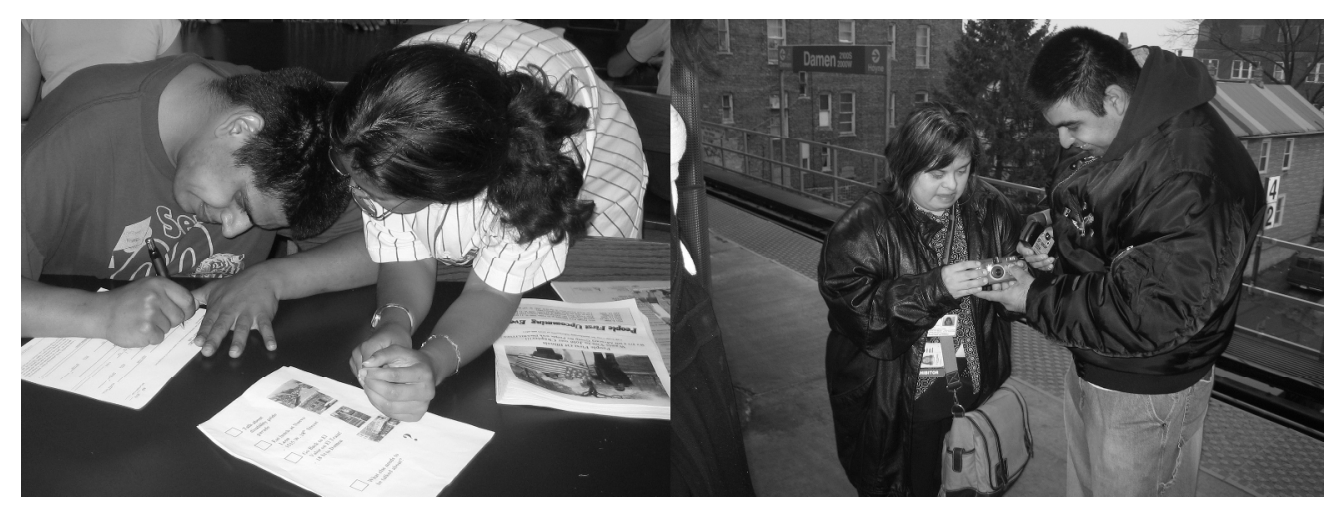

Figure 2. Peer social support and mentoring as depicted by participant photographs: 'Helping fill out library card' and 'I like to show how to take pictures.' 


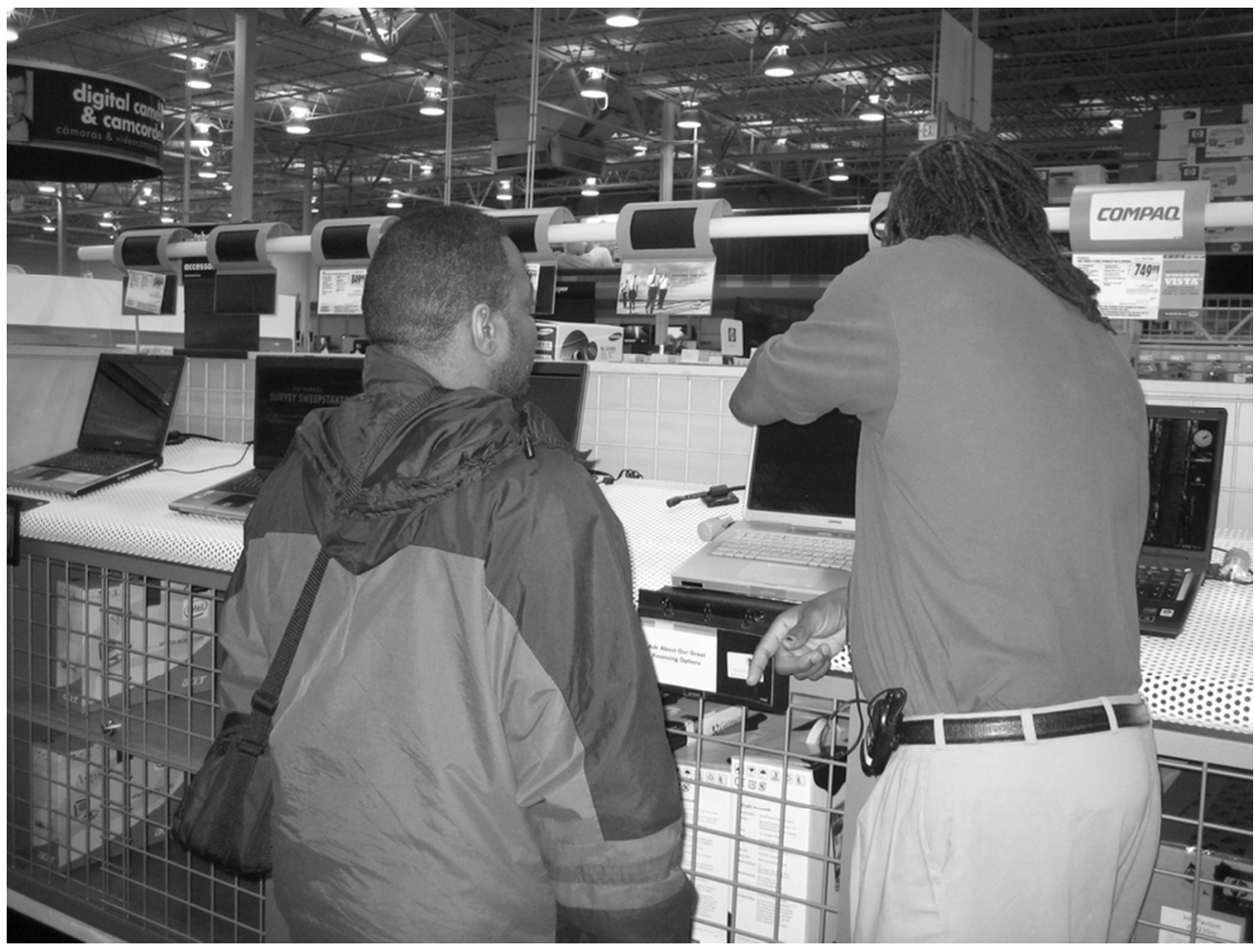

Figure 3. Positive societal attitudes as depicted by a participant photograph: 'Very helpful customer service rep.'

$82 \times 61 \mathrm{~mm}(300 \times 300$ DPI $)$ 


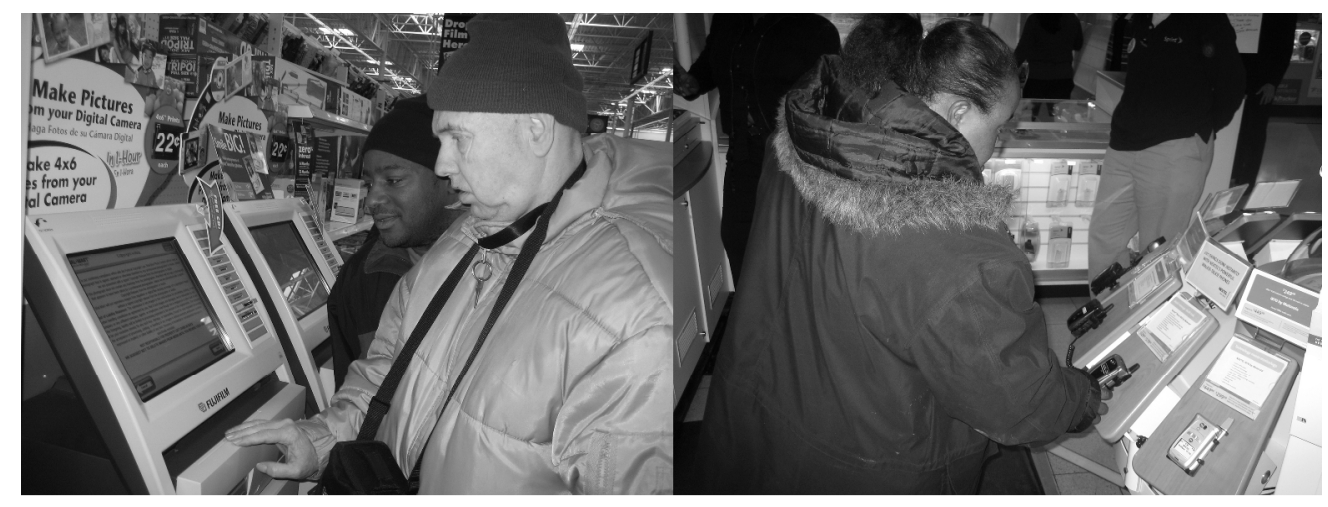

Figure 4. Lack of community access to technology as depicted by participant photographs: 'Not sure what to do with this page--too many words' and 'Trying out the cell phones- none work.' 
Figure 5. Lack of access to transportation as depicted by participant photographs: 'Difficult to get on bus. Large steps.' and 'Bus route does not run during the day- have to walk a long way.' 
Figure 6. Participation barriers and supports model. Adapted from Bronfenbrenner U, editor. Making human beings human: Biological perspectives on human development. Thousand Oaks: Sage Publications; 2005.

esire to be peer mentor due to past experiences being a mentee Chronosystem In

(1)
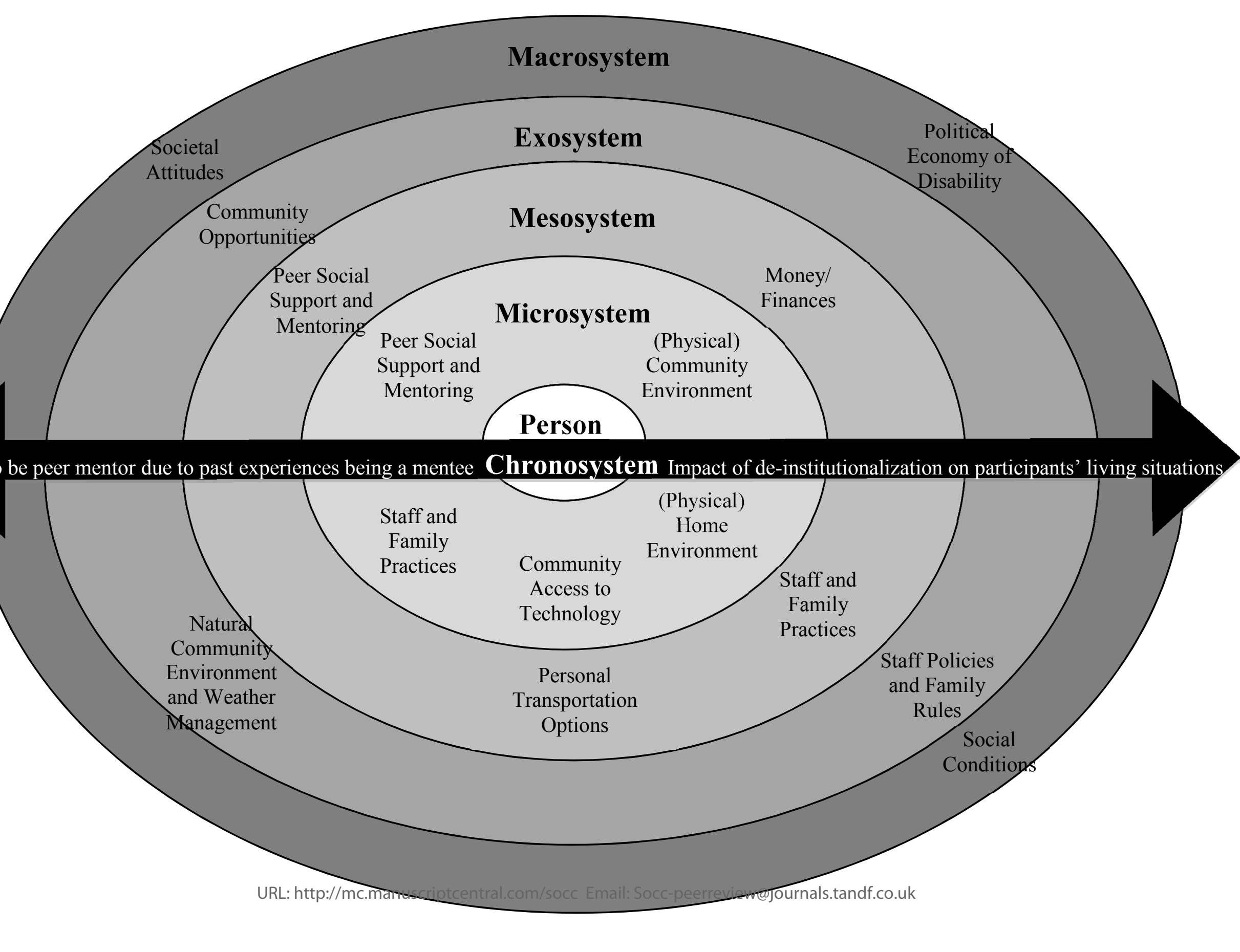

Staff and

$$
\text { Family }
$$

Practices

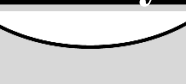

(Physical)
Home

Home
Environment

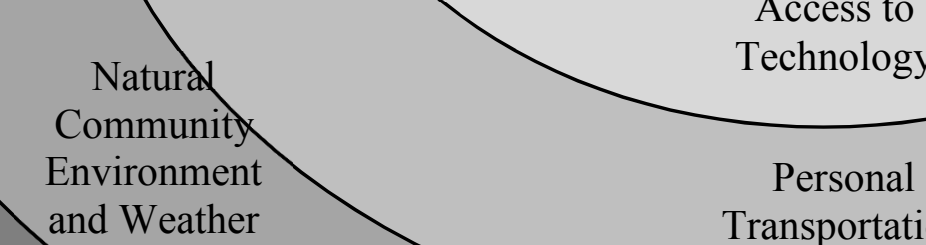

Management

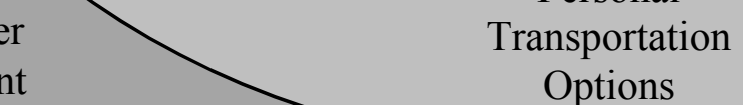

Options
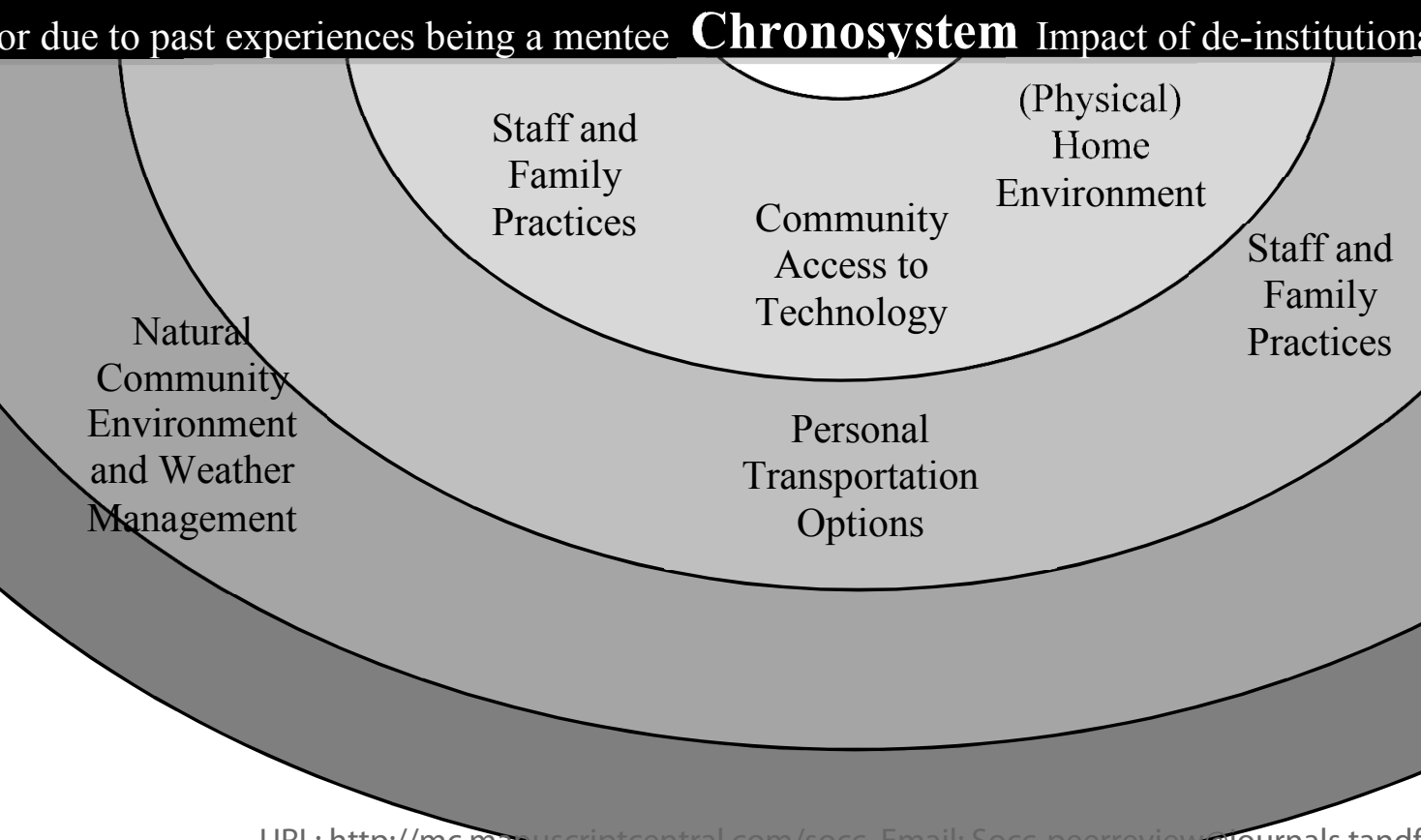

URL: http://mc.mar

Staff Policies and Family Rules Social Condition 